\title{
Development of a Fire Alarm Class Taken by Students from Two-Year Colleges
}

\author{
Prof. Harry Franz, P.E. \\ University of Houston Downtown
}

\begin{abstract}
The purpose of this paper is to discuss the development of an innovative Fire Alarm Class taken by students from two-year colleges by using new and original software exercises.

The University of Houston Downtown in Houston, Texas has a four-year Safety and Fire Engineering Technology program with a fire protection course, which in the catalog is formally named Fire Suppression and Detection Systems. The course is often referred to as the fire alarm system course.
\end{abstract}

The fire alarm system course development includes the design and use of detection, signaling and suppression systems. The course laboratory has both software and hardware. LabVIEW computer software is being used to develop new standalone software projects, and new project designs that interact with hardware.

Many of the fire alarm system class students are often fire and safety personnel that work in various related professions. Additionally, the class students have varied technical experience level and background in academics. The LabVIEW software is being used to develop a laboratory that is suitable for a class with students that have different backgrounds.

Newly developed laboratory exercises are used to acquaint the safety and fire students with LabVIEW and fire alarm systems.

Original LabVIEW exercises have been developed for the detection of fire signatures. Fire signatures include smoke, heat, and other changes in ambient conditions. These exercises also include the logic used to activate alarm signaling and fire suppression. Note that digital logic and analog functions are used.

Lab exercises range from the very basic concepts of fire protection systems and use of the fundamental LabVIEW features, to more advanced alarm system concepts and LabVIEW features. The capstone design project for the course requires a proficiency in LabVIEW. 
The University of Houton-Dowtown Engineering Technology department Safety and Fire four-year program has a Fire Detection, Alarm and Suppression course, which is taken by many students that come from two-year schools. The on-going development of the laboratory for this course is the topic of this paper.

The original goal and on-going goal is to develop a laboratory that is student friendly. It must be readily accessible, contain software and hardware that is user-friendly, and one that can be used by students that have various backgrounds. The on-going development includes newly created exercises and projects. The projects are designed by predominately using LabVIEW. The hardware projects also use logic controllers to implement the software LabVIEW designs.

First, basic LabVIEW is taught to the students by using basic fire alarm system examples. Note that the concept of concurrently teaching LabVIEW software and fire alarm systems is used throughout the course. As the level of understanding LabVIEW increases, the complexity of the fire alarm system examples also increases.

An example of one such exercise is shown in figures $1 \& 2$ below. The figures show basic system that compares the set point to the actual temperature of the thermometer. If actual temperature is greater than the set point an alarm signals. Note that the door of the panel and system switch both must be closed. An " $A N D$ " gate determines this and enables the system to activate.

Figure 1. LabVIEW panel view of basic temperature alarm system

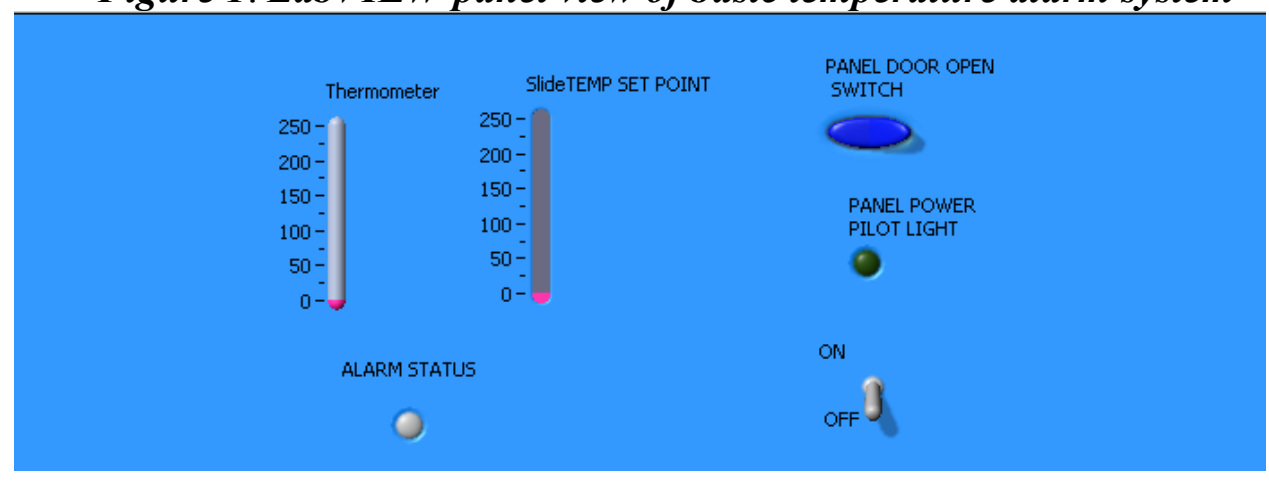

Figure 2. Corresponding diagram view for the panel just above

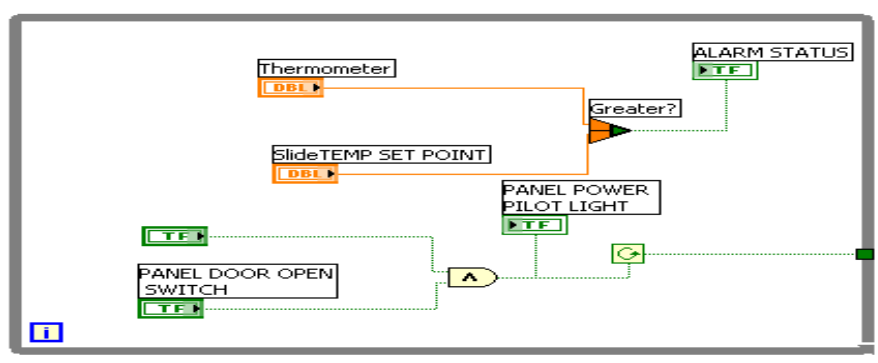

Proceedings of the 2005 American Society for Engineering Education Annual Conference \& Exposition Copyright@2005 American Society for Engineering Education 
Another example of a student exercise that is a little more complex than the previous one just given, is shown in figures $3 \& 4$ below. This one of many exercises that progress the students in both LabVIEW and fire alarm systems.

This example shows a system that compares the actual temperature of the thermometer to its setpoint, and compares the smoke level to its smoke level set point. If the set value of either temperature or smoke is exceeded, a fire signature is indicated and only the respective temperature or smoke alarm signals. If both temperature and smoke alarms signal, then the general alarm signals. An on/off switch controls the system activation.

Figure 3. LabVIEW panel view of student exercise fire alarm system

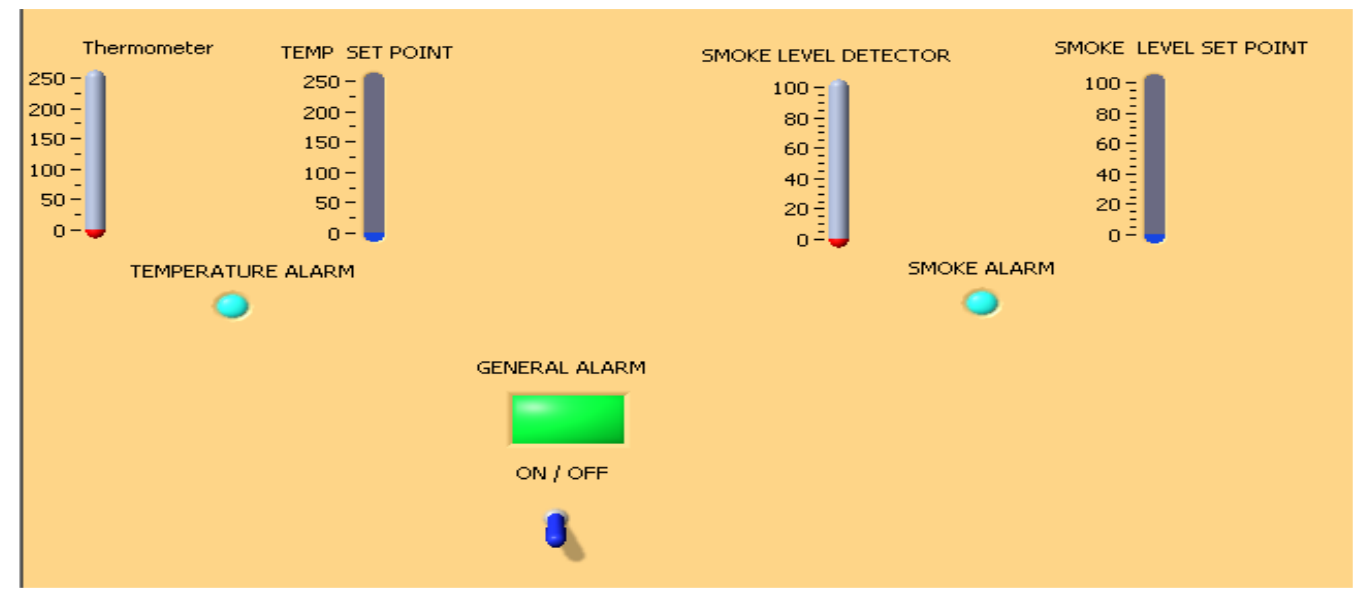

Figure 4. Corresponding diagram view for the panel just above

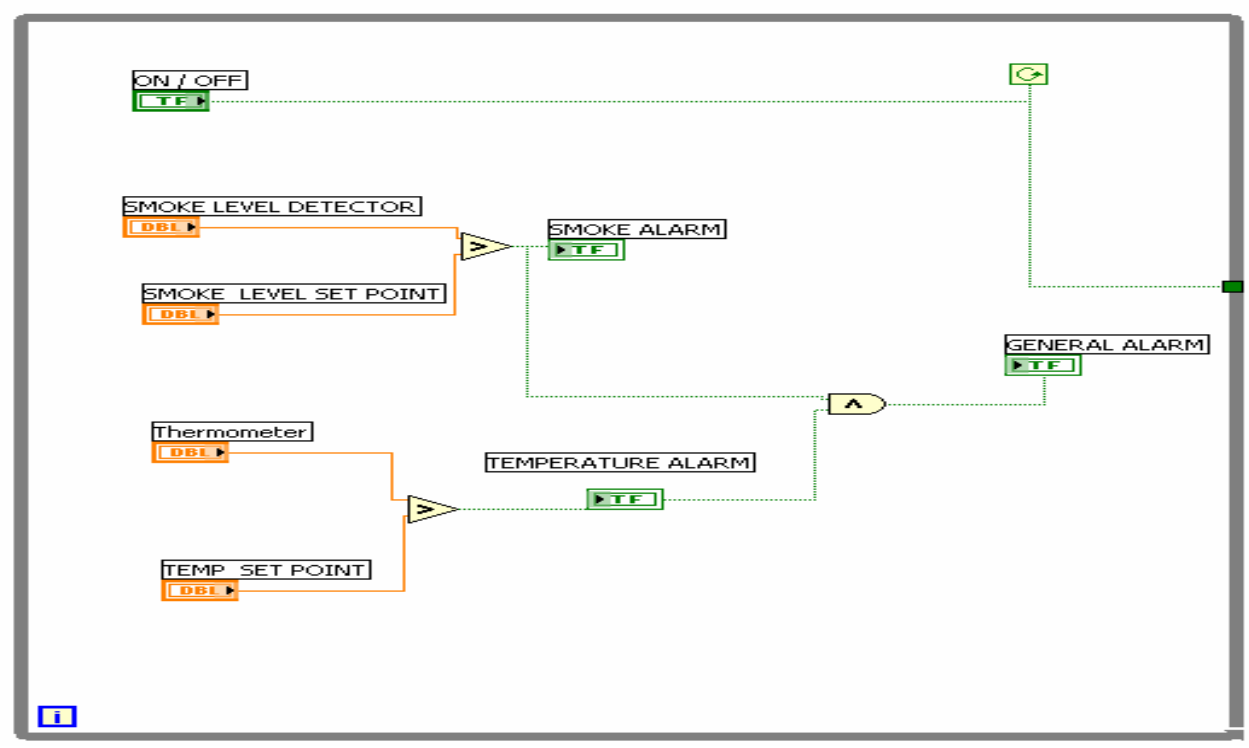

Proceedings of the 2005 American Society for Engineering Education Annual Conference \& Exposition Copyright@2005 American Society for Engineering Education 
As the students progress, the class project is assigned. The students work in groups, but each student must write a formal report and participate in a demonstration of the working project. The project has a software part that predominately uses LabVIEW and a hardware part that uses logic control and LabVIEW. The project figure 5. shown just below has been designed using LabVIEW. It shows fire detection, alarm, suppression, and evacuation industrial fire protection system.

The project works per the following.

A local alarm will signal only for its area when there is smoke in the respective area Local alarms signal for the immediate area and adjacent areas if there is high-heat. Local alarms signal for the immediate area and adjacent areas if there are chemicals. A general alert alarm signals if two areas detect any fire signature.

The evacuate alarm signals if the UV activates, or if more than two areas detect. There is an "activate / reset" button for system.

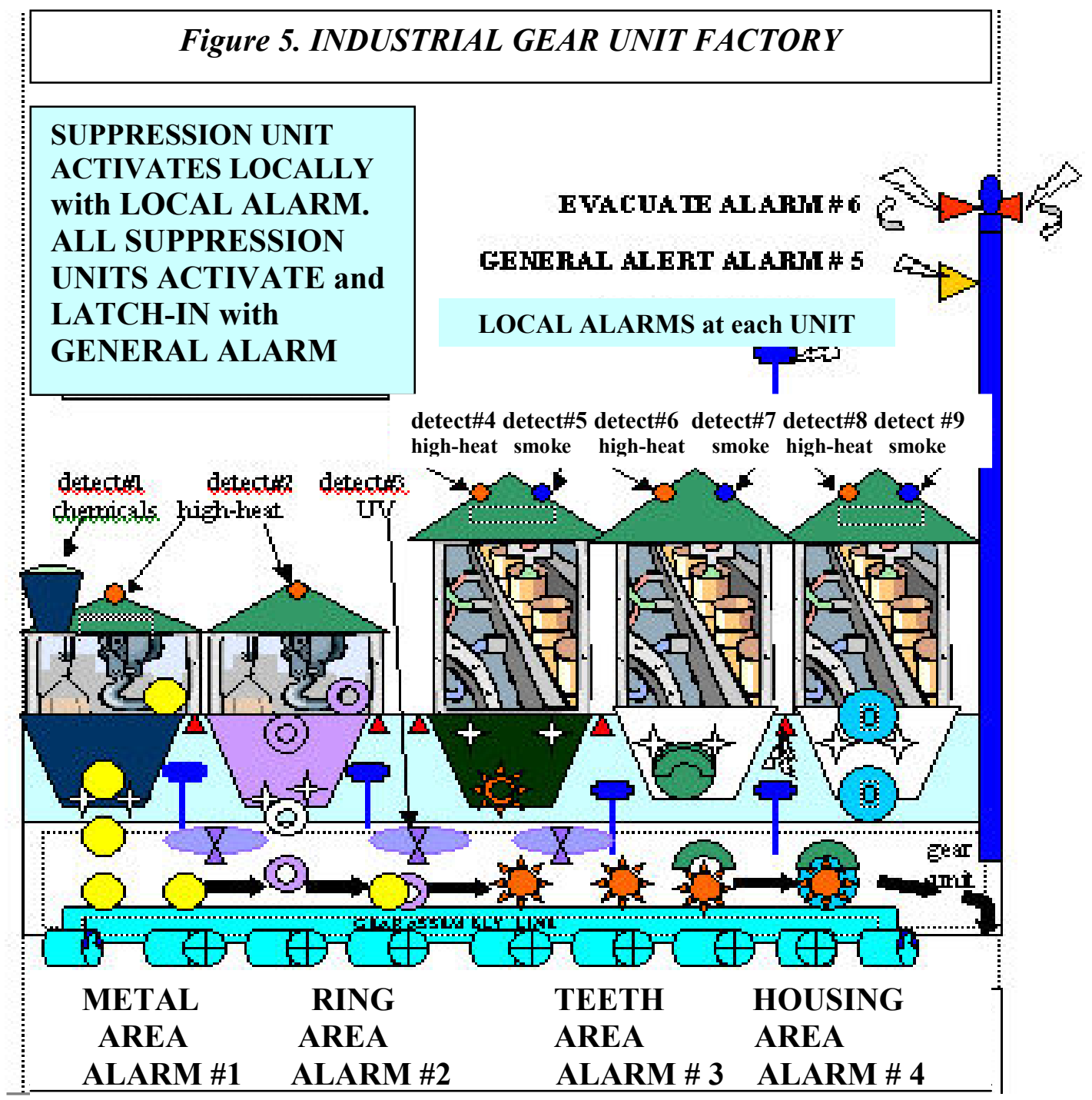

Proceedings of the 2005 American Society for Engineering Education Annual Conference \& Exposition Copyright@2005 American Society for Engineering Education 
The hardware panel for the industrial fire alarm system previously just described is figure 6 . The system has detectors for smoke. Heat, ultraviolet, and chemicals all of which can indicate fire signatures. The logic was designed using LabVIEW and is the basis for the control logic of the hardware panel.

Figure 6. Hardware panel for fire alarm system with detection, suppression and evacuation

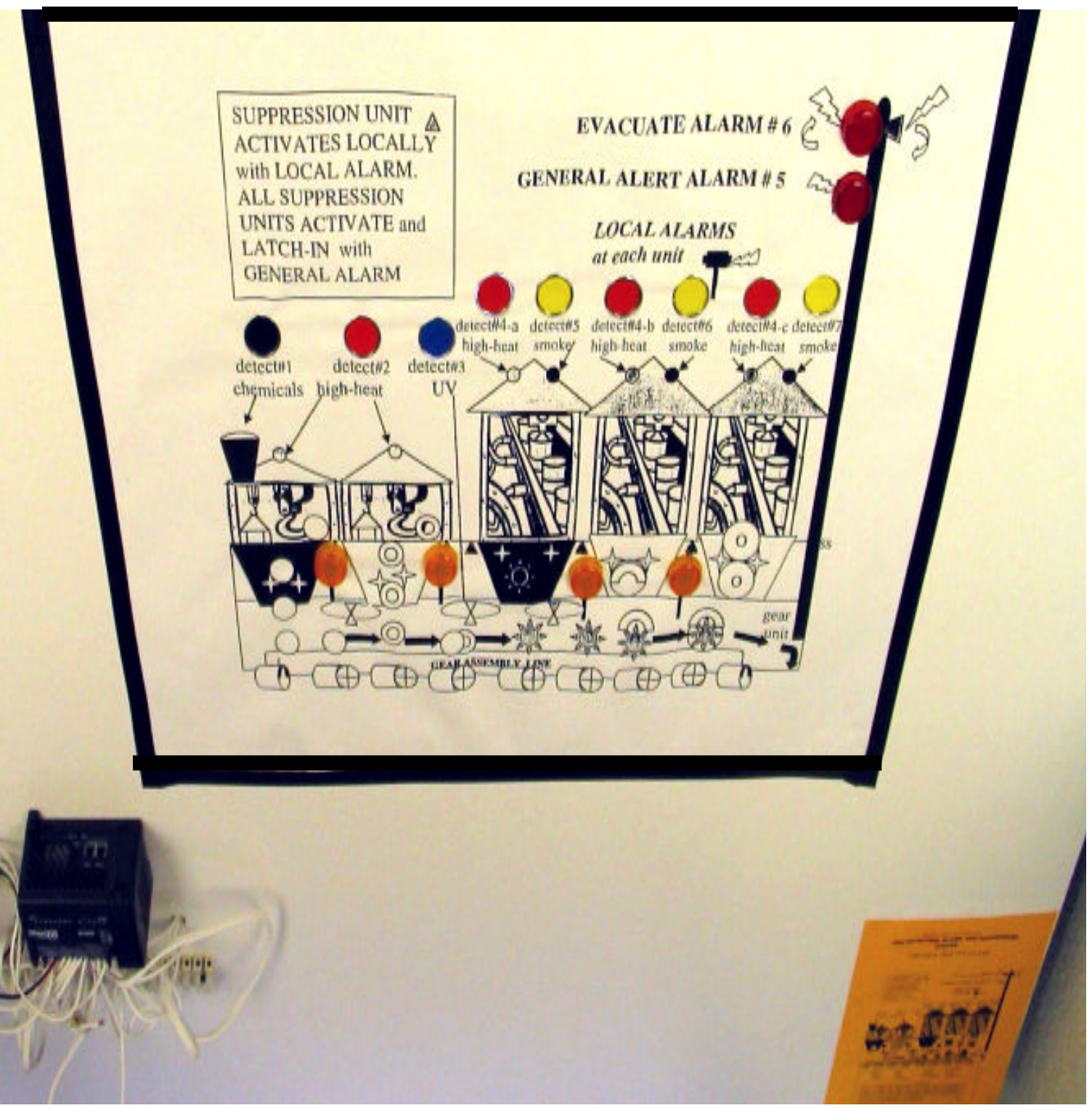

Proceedings of the 2005 American Society for Engineering Education Annual Conference \& Exposition Copyright@2005 American Society for Engineering Education 
Another project for a school detection and alarm evacuation system follows. First a simplified example is given to serve as a basis for the larger more complex total project as shown in figure 7 and figure 8 below. These class examples and exercises build the students knowledge of both LabVIEW and fire protection systems.

Figure 7. LabVIEW panel of simplified school detection \& alarm evacuation example.

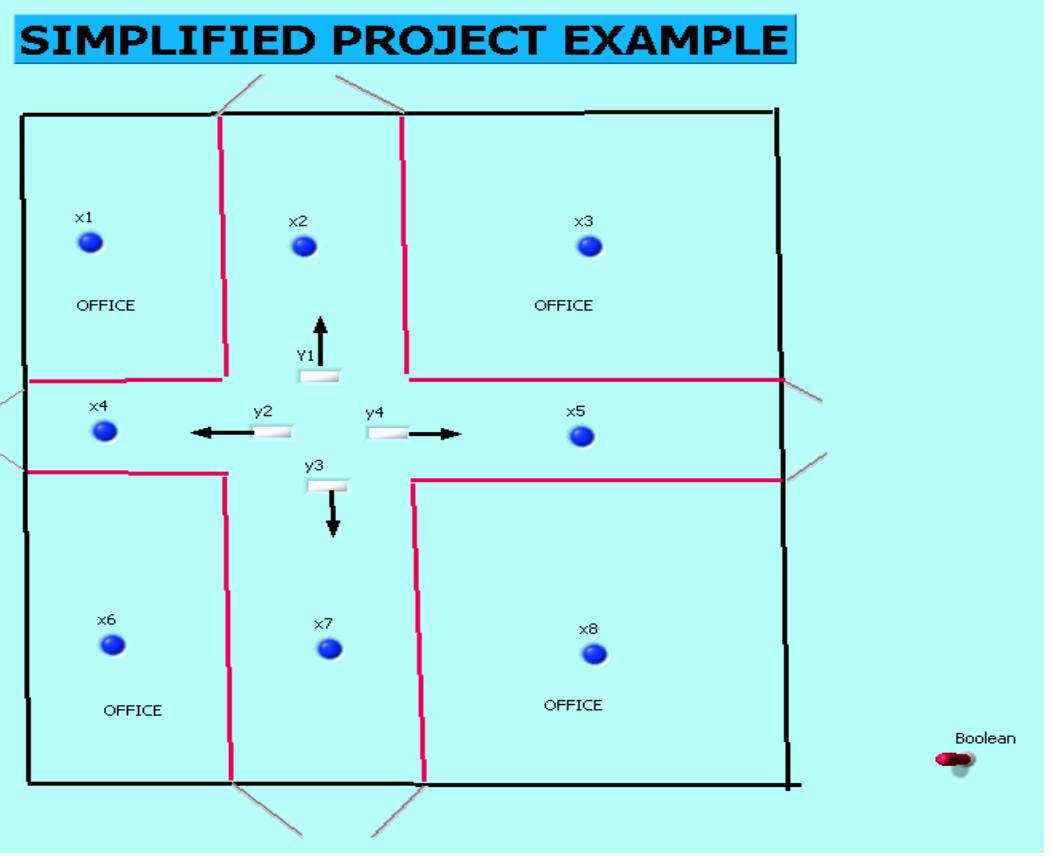

Figure 8. LabVIEW diagram view of school detection and alarm evacuation system above

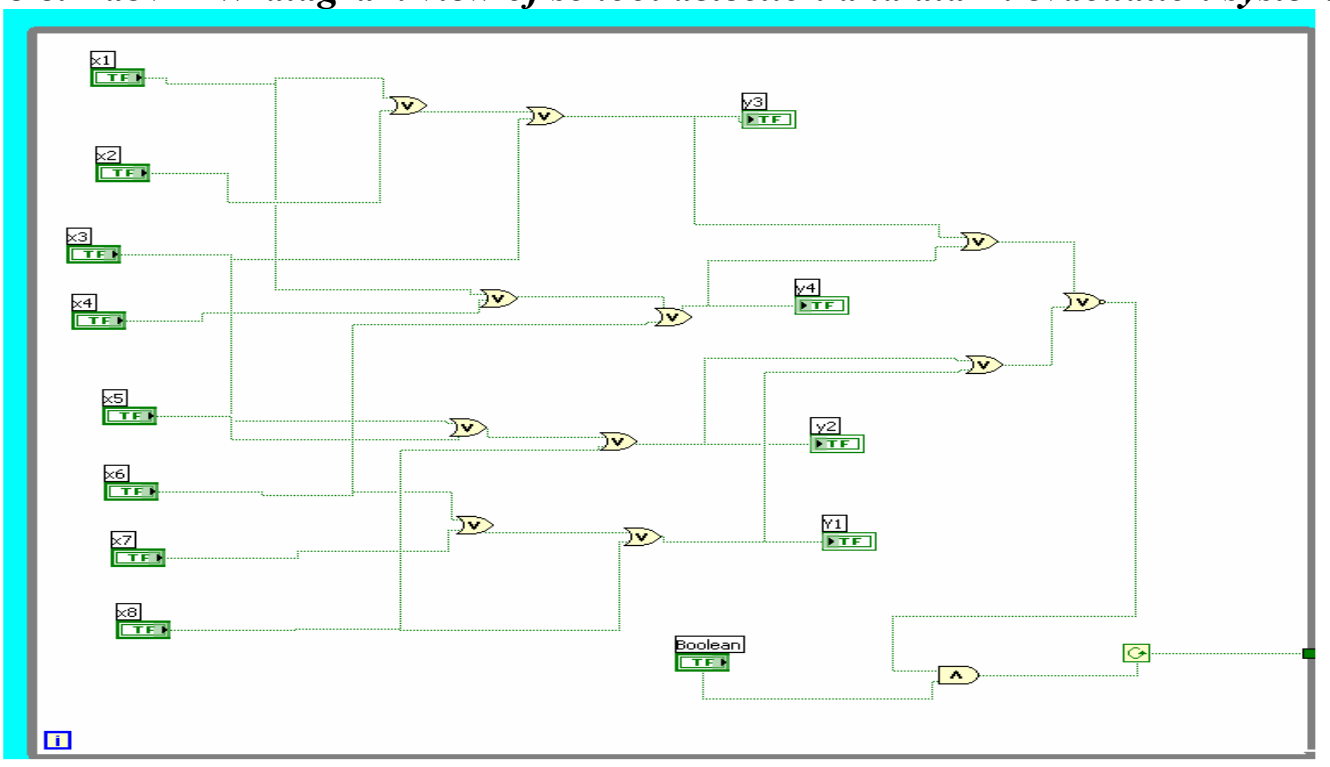

Proceedings of the 2005 American Society for Engineering Education Annual Conference \& Exposition Copyright@2005 American Society for Engineering Education 
Next is the student project design for the fire detection, alarm, and evacuation system for a school building as shown in figures 9 and 10 below.

If any detector has a fire signature, all alarms alert. In addition, the evacuation system guides the evacuation away from the fire signature areas to the proper exits.

Figure 9. Student project for fire detection alarm \& evacuation for a school building.

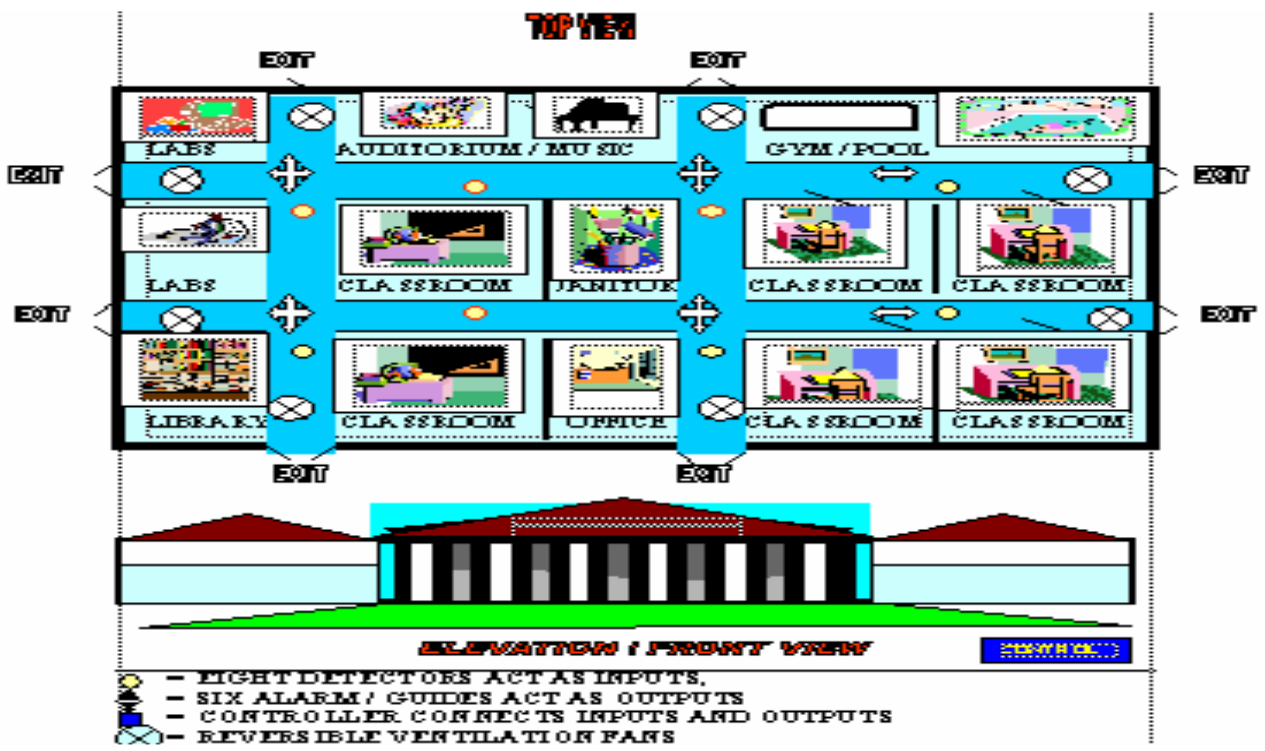

Figure 10. Hardware panel for fire detection, alarm, \& evacuation system shown above

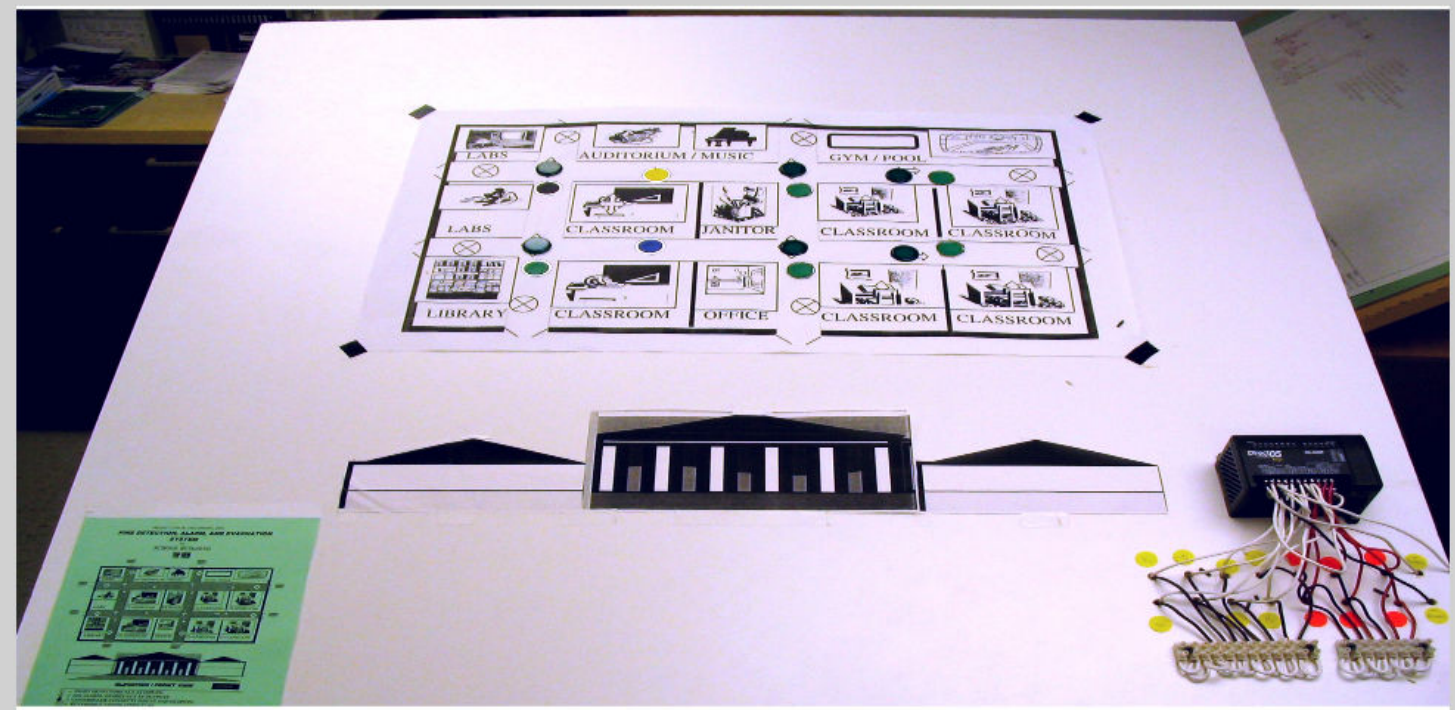

Proceedings of the 2005 American Society for Engineering Education Annual Conference \& Exposition Copyright@2005 American Society for Engineering Education 
The development of an innovative Fire Alarm Class taken by students from two-year colleges by using new and original software exercises has been shown.

The development further continues with new exercises and projects that predominately use LabVIEW for the design of detection, signaling and suppression systems. The design is used in the laboratory for both software and hardware. The LabVIEW computer software also further continues to be used to develop new standalone software projects, and new project designs that are used with hardware and logic controllers.

The fact that many of the class students have varied technical experience level and background in academics has been overcome by the continued use of LabVIEW in the development of the course laboratory. This has resulted in the creation of a laboratory that is suitable for use by students that are from various two-year schools and that have different backgrounds.

A demonstration of the LabVIEW software exercises and projects will be given.

\section{Bibliography:}

1. UHD ENGR-1403 STUDENTS, projects Fall 2003

2. UHD ENGR-1403 STUDENTS, projects Fall 2004

3. LabVIEW 6i Student Edition

Prentice Hall

National Instruments

4. Learning with LabVIEW

Prentice Hall

by ROBERT BISHOP

5. LabVIEW 7 EXPRESS

Prentice Hall

National Instruments

\section{Biography}

HARRY FRANZ is an Associate Professor of Control \& Instrumentation Electronics Design and Safety \& Fire Engineering Technology at the University of Houston-Downtown. He received a BSEE with honors and an MSEE from the University of Pittsburgh. He also has credits towards a PhD.EE, a P.E. registration by NCEES exam and sixteen years experience in industry. He is a member of ASEE, IEEE, ISA. NSPE, and TAP.

Proceedings of the 2005 American Society for Engineering Education Annual Conference \& Exposition 